4. Ярославцев А.Г., Фатькин К.Б. Шахтные сейсмоакустические исследования при контроле предохранительных целиков в калийных рудниках //. Инженерная и рудная геофизика -2020 : 16-я науч.-практ. конф. и выставка, 14-18 сент. 2020. - Пермь, 2020. - DOI: 10.3997/22144609.202051043.

5. Бобров В.Ю. Оптимальные пути подавления боковых волн-помех при цифровой обработке шахтных сейсмоакустических данных // Горное эхо. - 2021. - № 1 (82). - С. 68-74.

УДК 550.8.052

DOI:10.7242/echo.2021.2.13

\title{
МЕТОД РЕДКИХ СОЧЕТАНИЙ ПРИ ВЫДЕЛЕНИИ ЗОН ИНЖЕНЕРНО-ГЕОЛОГИЧЕСКИХ ОСЛОЖНЕНИЙ ПО ЭЛЕКТРОРАЗВЕДОЧНЫМ ДАННЫМ
}

\author{
Л.А. Христенко \\ Горный институт УрО РАН, г. Пермь
}

\begin{abstract}
Аннотация: Для повышения достоверности интерпретации электроразведочных наблюдений методами естественного поля и симметричного электропрофилирования, выполненного на трех разносах питающей линии, предложено использовать метод редких сочетаний. Метод основан на расчете суммарных матриц относительных частот встречаемости различных параметров. Минимальные значения параметра МРС (суммарные частости) отвечают аномальным - редким сочетаниям всех использованных признаков. Метод был опробован на участке, расположенном в пределах шахтного поля СКРУ-2 Верхнекамского месторождения солей. Исходными признаками для вычисления параметров МРС служили статистические характеристики электрических параметров (значений потенциала ЕП и значений кажущегося сопротивления). Сравнение результатов интерпретации, полученных с использованием параметров МРС и результатов классификаций методом общего расстояния, между собой показало, что области предполагаемых инженерно-геологических осложнений устойчиво выделяются двумя методами, имеющими различный математический аппарат. Т.е. каждый из методов повышает достоверность выделенных осложнений природного или техногенного происхождения.
\end{abstract}

Ключевые слова: кажущееся сопротивление, потенциал естественного поля, статистические характеристики, метод редких сочетаний.

Интерпретация данных электроразведочных методов естественного поля (ЕП) и симметричного электропрофилирования (СЭП), входящих в комплекс методов, используемых при решении различных геологических и горнотехнических задач, связанных с обеспечением эффективности и безопасности отработки соляных месторождений, чаще всего основана на простейших приемах оценки глубин залегания и размеров источников или на качественном анализе. Такие приемы интерпретации приводят к неоднозначным выводам. Достоверность и информативность интерпретации можно повысить, используя различные преобразования электрометрических параметров. Преобразования позволяют более четко проследить неявно выраженные в наблюденных полях особенности геологического строения. Результаты использования процедур безэталонной классификации, быстрого вейвлет-преобразования дискретных значений кажущегося сопротивления (КС); методы эмпирической модой декомпозиции (EMD) уже были подробно представлены ранее $[4,5,10,11]$. В [9] дана краткая ретроспектива определения эффективного набора процедур преобразования данных ЕП и СЭП. Кроме того, рассмотрен еще один метод безэталонного прогнозирования или эвристический метод выделения аномальных зон по комплексу признаков - метод редких сочетаний (МРС), впервые предложенный в 1973 году Н.Н. Боровко [1].

Суть метода состоит в том, что в каждой точке задания поля выполняется расчет относительной частоты его встречаемости, рассчитанной как отношение числа зна- 
чений поля, попадающих в заданный интервал амплитуд, к общему числу точек. Матрицы относительных частот рассчитываются для различных геофизических полей, их трансформант, формализованных геологических признаков. Результативная матрица представляет собой суммарный частотный спектр. Минимальные значения параметра МРС отвечают наиболее редким сочетаниям всех использованных признаков.

Эффективность использования МРС для электроразведочных параметров была подтверждена сопоставлением результатов его использования с результатами, полученными ранее методом общего расстояния на участке, расположенном в пределах шахтного поля БКПРУ-2 Верхнекамского месторождения калийно-магниевых солей. Использованные ранее процедуры безэталонной классификации, реализованные в Комплексе спектрально-корреляционного анализа данных КОСКАД [7], позволили разбить анализируемые совокупности на однородные по формальным математическим критериям классы, пространственно отвечающие участкам возможных инженерно-геологических осложнений, что крайне затруднительно по результатам только качественного анализа полевых наблюдений. Отмечалось пространственное совпадение контуров классов с осложнениями волнового поля, полученными по результатам сейсмических исследований [10]. Поэтому результаты классификаций в «КОСКАД» послужили основой для оценки достоверности метода МРС.

Области предполагаемых инженерно-геологических осложнений устойчиво выделились двумя методами безэталонного прогнозирования, имеющими различный математический аппарат, что еще раз подтвердило существование осложнений природного и техногенного происхождения [9].

«Геологическое истолкование электроразведочных материалов требует учета конкретной ситуации - литологического состава пород, возможных фациальных изменений, степени минерализации вод и т. п. Часто в результате существующих причинно-следственных связей общий эффект от влияния разных факторов усиливается, например, при гидрогеологических исследованиях повышение трещиноватости и разуплотненности пород увеличивает количество водосодержания, что в свою очередь более активизирует процессы выщелачивания пород, повышая тем самым минерализацию водных растворов. Совокупное наличие этих факторов, каждый из которых направлен на уменышение сопротивления породы, приводит к суммарному эффекту, проявляющемуся в образовании резко выраженных аномалий пониженного электрического сопротивления, что является диагностическим признаком для картирования подобных зон. В то же время породы, обладающие хорошей фильтрационной способностью (пески, галечники, выветрелые известняки и др.) являются наиболее изменчивыми по сопротивлению, величина которого, вследствие разной степени их водонасыщения и минерализации вод, может колебаться в значительных пределах (до нескольких порядков)» [6]. При интерпретации СЭП контуры выделенных классов помогают более достоверно определить границы зон развития описанных процессов. Наиболее содержательные классы, полученные над пестроцветной толщей (в пределах БКПРУ-2), характеризуются устойчивыми пониженными средними значениями сопротивления. В пределах СКРУ-2 средние значения в контурах геологически содержательных классов не устойчивы во времени и могут отличаться от фоновых значений в сторону увеличения. Классы более четко, чем средние значения исходных параметров электрических полей, отражают контрастные по физическим свойствам зоны. Для дальнейшей проверки эффективности использования МРС был выбран участок в пределах СКРУ-2, на котором ранее выполнялись все описанные преобразования электрических параметров [10], как на участке в пределах БКПРУ-2 [11].

Задачей электроразведочных методов было выделение и оконтуривание участков инженерно-геологических осложнений и прослеживание динамики изменения во времени, характера их поведения и положения на профилях наблюдений. Наблюдения выполня- 
лись по 4 профилям методами естественного поля и трехразносного симметричного электропрофилирования с разносами питающей линии $\mathrm{AB}=100,200$ и 400 м (рис. 1).

a)

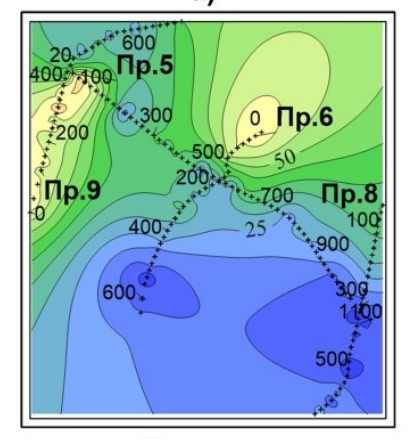

б)

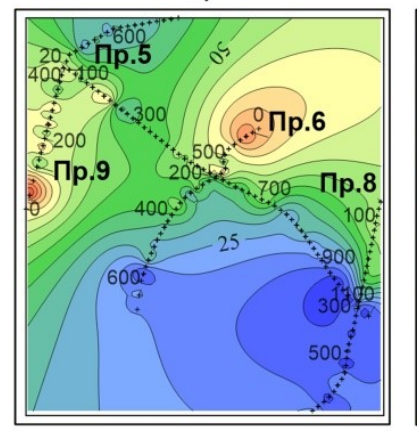

в)

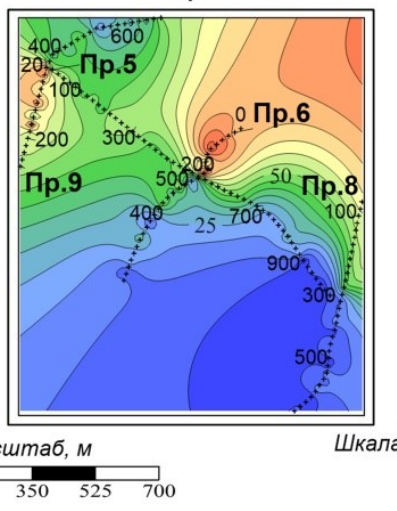

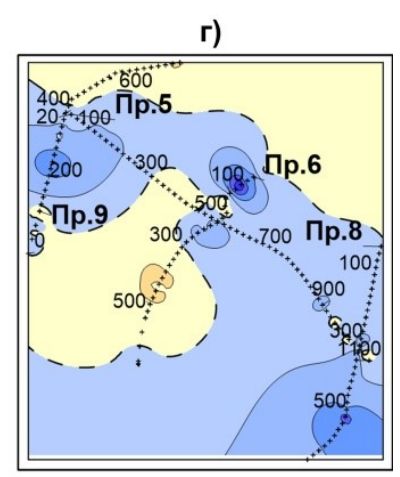

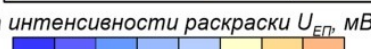
$-60$

Рис. 1. Планы изоом кажущегося сопротивления, наблюденного методом СЭП с разносами АВ: $\mathrm{a}-100$ м; б - 200 м; в - 400 м, и изолиний естественного электрического поля (г)

Исходными признаками для вычисления параметров МРС служили статистические характеристики электрических параметров (значений потенциала ЕП и значений кажущегося сопротивления - КС), рассчитанные в скользящих окнах программным комплексом КОСКАД 3D [8]. Для каждого параметра было рассчитано по пять статистик: среднее; дисперсия; коэффициенты вариации, асимметрии и эксцесса. В программе MRS [3] рассчитывались матрицы относительных частот статистик электрических параметров и матрицы параметров МРС (суммарные матрицы относительных частот). Матрицы параметров МРС были рассчитаны для различных комбинаций статистик, с учетом разносов питающей линии АВ. Одна матрица МРС не могла включать относительные частоты статистик КС, измеренных на разных разносах линии АВ. Например, для комбинации из 2 признаков были рассчитаны 3 матрицы параметров МРС, как суммы относительных частот:

- средних значений потенциала ЕП и КС, измеренных на разносе $\mathrm{AB}=100$ м;

- средних значений потенциала ЕП и КС, измеренных на разносе $\mathrm{AB}=200$ м;

- средних значений потенциала ЕП и КС, измеренных на разносе $\mathrm{AB}=400 \mathrm{M}$.

Другая комбинация статистик для расчета МРС включала средние и дисперсии значений потенциала ЕП и КС, измеренных на разных разносах линии $\mathrm{AB}$, т.е. 3 матрицы параметров МРС, каждая из которых рассчитывалась как сумма из 4 матриц относительных частот. Расчет параметров МРС выполнялся и для комбинации дисперсии с другими статистиками значений потенциала ЕП и КС (коэффициентами вариации, асимметриями, эксцессами), а также для всех 10 статистик (5 статистик значений потенциала ЕП и 5 статистик значений КС) на трех разносах линии АB.

Ранее с этими же исходными признаками были выполнены процедуры безэталонной классификации, реализованные в «КОСКАД 3D». Классификация методом общего расстояния позволила получить наиболее содержательные классы. Эвристические методы классификации, в «КОСКАД 3D» основаны на разбиении диапазона значений каждого признака на заданное число градаций и в большинстве своем сводятся к расчету комплексного параметра, который является линейной комбинацией соответствующего номера интервала градации по совокупности анализируемых признаков в каждой точке наблюдений.

На рис. 2 для сопоставления приводятся области, выделенные двумя эвристическими методами: в результате классификации методом общего расстояния (рис. 2а) и с по- 
мощью параметра МРС (рис. 2б-г), рассчитанного для различных комбинаций статистических характеристик значений потенциала естественного поля и кажущегося сопротивления с линией $\mathrm{AB}=100 \mathrm{M}$.

a)

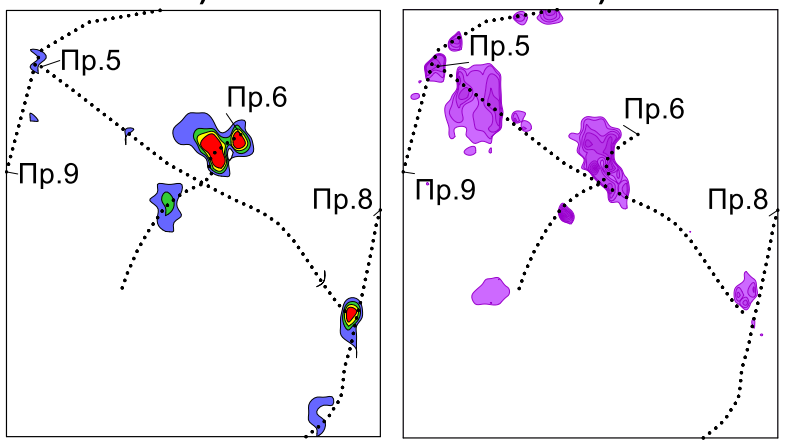

B)

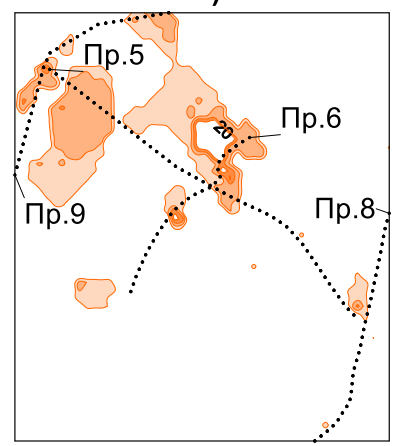

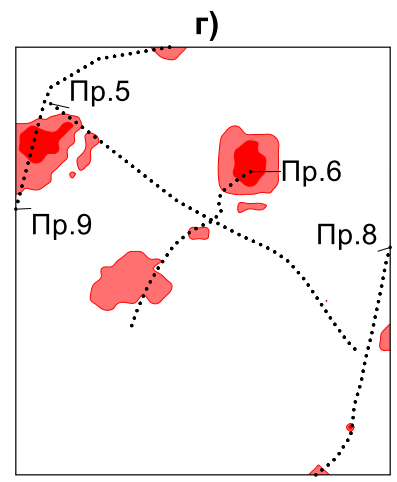

Рис. 2. Результаты классификации методом общего расстояния (а) и параметры МРС, рассчитанные:

б) по 10 статистикам; в) по 4 статистикам и г) по 2 статистикам.

Примечание: используемые КС получены при измерениях с линией $A B=100 \mathrm{м}$

На рис. 3 и 4 приведены результаты вычислений, но с КС, полученными на разносах $\mathrm{AB}=200$ и 400 м, соответственно. Видно, что наилучшее пространственное совпадение результатов классификации получено с параметром МРС, вычисленным по 4 признакам: средним и дисперсиям значений потенциала ЕП и кажущегося сопротивления для всех разносов питающей линии.

a)

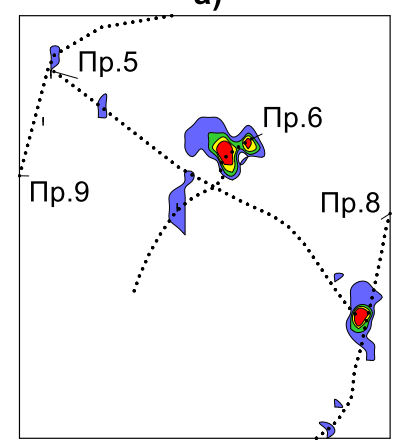

б)

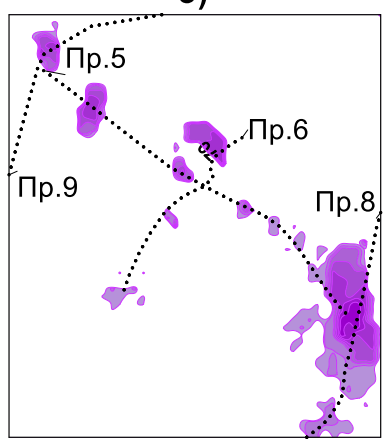

B)

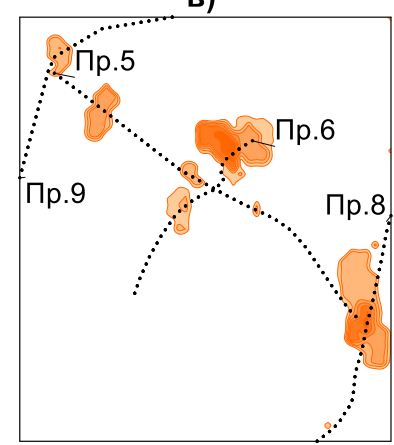

г)

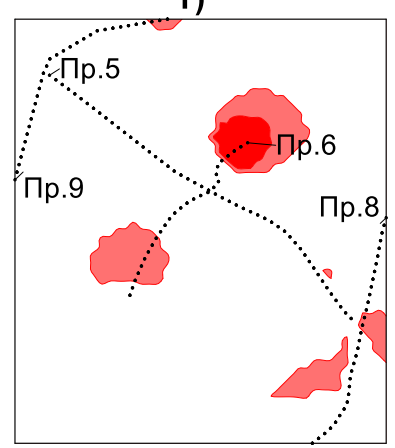

Рис. 3. Результаты классификации методом общего расстояния (а) и параметры МРС, рассчитанные: б) по 10 статистикам; в) по 4 статистикам и г) по 2 статистикам.

Примечание: используемые КС получены при измерениях с линией $A B=200 \mathrm{M}$

a)

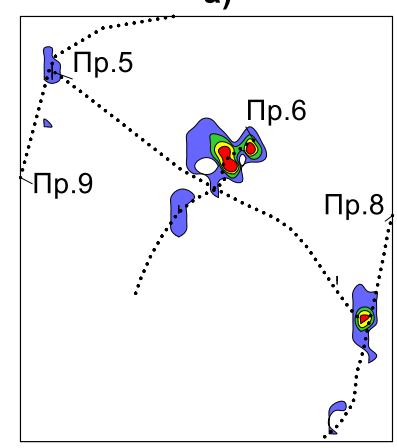

б)

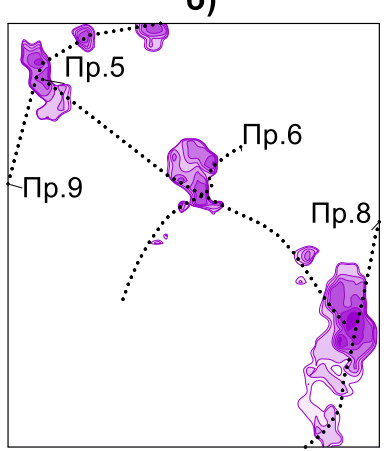

в)

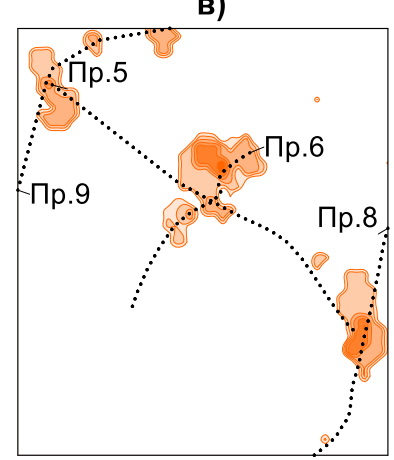

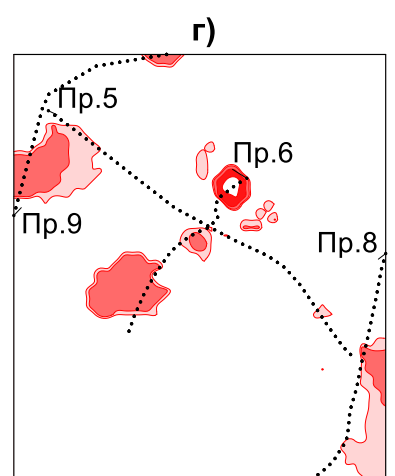

Рис. 4. Результаты классификации методом общего расстояния (а) и параметры МРС, рассчитанные: б) по 10 статистикам; в) по 4 статистикам и г) по 2 статистикам.

Примечание: используемые КС получены при измерениях с линией $A B=400 \mathrm{м}$ 
Параметры МРС, рассчитанные для комбинаций дисперсий с асимметриями и дисперсий с эксцессами, тоже имеют хорошее пространственное совпадение с результатами классификаций. Максимальные значения дисперсии тяготеют к границам аномальных областей. Минимальные и максимальные значения асимметрии и эксцесса также приурочены к границам аномалий. Этим объясняется наилучшее совпадение контуров содержательных классов с областями параметров МРС, вычисленных для комбинаций, включающих эти статистические характеристики.

Области предполагаемых инженерно-геологических осложнений, как и на участке в пределах БКПРУ-2 [9], устойчиво выделяются двумя эвристическими методами. Использование двух методов безэталонного прогнозирования, имеющих различный математический аппарат, позволяет повысить достоверность полученных результатов.

Пространственное положение контуров классов сопоставлялось с результатами сейсмических исследований и газогеохимического опробования. На всех 4 профилях были отмечены совпадения контуров выделенных классов (по данным электроразведки) с осложнениями волнового поля и контурами газогеохимических аномалий.

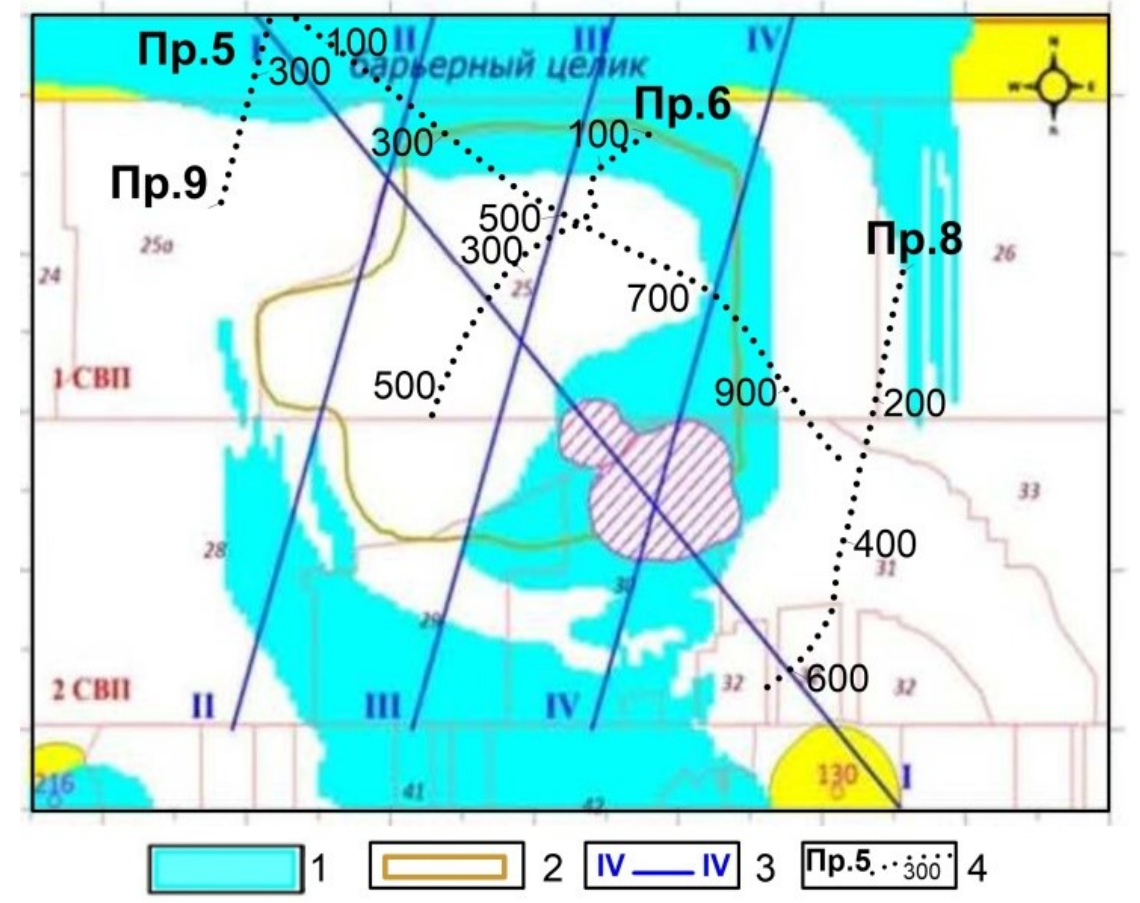

Рис. 5. Распределение зон техногенной трещиноватости в верхней части ТКТ [2]: 1 - зона техногенной трещиноватости; 2 - зона обрушения; 3 - разрез; 4 - профили электроразведочных наблюдений

Численная реализация трехмерного математического моделирования позволила получить распределение областей техногенной нарушенности по сечениям в интервале надсоляной толщи и вертикальным разрезам [2]. По результатам моделирования установлено, что в нижней части ТКТ трещиноватость охватывает все границы зоны обрушения, за исключением юго-западной (рис. 5). В ее верхней части разрушения отмечаются на барьерном целике, северной и восточной границах зоны обрушения.

Обширная область трещиноватости фиксируется в южной части исследуемого участка, подходя к зоне обрушения с юго-запада. Область хорошо видно на секущем разрезе I-I [2], с ней согласуются выделенные на Пр. 8 контуры классов и области параметров МРС. По контурам классов и областей, выделенных с помощью параметров МРС, полученных для различных разносов питающей линии, можно проследить дина- 
мику их распространения и областей нарушенности породного массива, которые они отражают, по глубине. А контуры классов и области параметров МРС, полученные для многократных циклов наблюдений, позволяют прослеживать динамику изменения характера поведения и положение их на профилях наблюдений во времени.

Наиболее достоверным итогом комплексной интерпретации являются результаты, которые устойчиво выявляются в рамках различных моделей (методов) извлечения информации из исходных данных. Области предполагаемых инженерно-геологических осложнений устойчиво выделились двумя методами, имеющими различный математический аппарат в пределах двух исследуемых участков. Это позволяет включить метод редких сочетаний в число эффективных процедур преобразования данных ЕП и СЭП для повышения достоверности и информативности их интерпретации.

\section{Исследование выполнено при финансовой поддержке Министерства науки и образования РФ в рамках соглашения по государственному заданию № 075-03-2021-374 от «29» декабря 2020 г., а также при поддержке РФФИ (проект 19-05-00654 A).}

\section{БИБЛИОГРАФИЧЕСКИЙ СПИСОК}

1. Боровко Н.Н. Количественный анализ поисковых критериев крупных эндогенных рудных месторождений // Веселов В.В. Месторождение важнейших металлических полезных ископаемых: Обзор. М., 1973. - 63 с. - (Геология, методы поисков и разведки месторождений металлических полезных ископаемых).

2. Девятков С.Ю. Геомеханическая оценка развития зон техногенной трещиноватости в надсоляной толще на аварийном участке рудника СКРУ-2 // Горное эхо. - 2020. - № 1 (78). - С. 37-42. - DOI: 10.7242/echo.2020.1.8.

3. Долгаль А.С. Компьютерные технологии обработки и интерпретации данных гравиметрической и магнитной съемок в горной местности. - Абакан: «Фирма» «МАРТ», - 2002. - 188 с.:ил. - Текст электронный. - URL: https://www.geokniga.org/bookfiles/geokniga-dolgal-as-kompyuternye-tehnologiiobrabotki-i-interpretacii-dannyh-gravime.pdf.

4. Долгаль А.С. Моделирование геологических объектов и геофизических полей с использованием вейвлетов Хаара // Вестн. Перм. ун-та. Сер. Геология. - 2014. - Вып. 4 (25). - С. 66-80. - DOI: 10.17072/psu.geol.25.66.

5. Долгаль А.С., Христенко Л.А. Применение эмпирической модовой декомпозиции при обработке геофизических данных // Изв. Томского политехнич. ун-та. Инжиниринг ресурсов. - 2017. - Т. 328. № 1. - С. 100-108.

6. Колесников В.П. Основы интерпретации электрических зондирований. - М.: Науч. мир, 2007. - 247 c..

7. Петров А.В., Трусов А.А. Компьютерная технология статистического и спектральнокорреляционного анализа трехмерной геоинформации - КОСКАД 3D // Геофизика. - 2000. - № 4, C 29-33.

8. Петров А.В., Юдин Д.Б., Хоу Сюели. Обработка и интерпретация геофизических данных методами вероятностно-статистического подхода с использованием компьютерной технологии «КОСКАД 3D» // Вестник КРАУНЦ. Науки о Земле. - 2010. - № 2, Вып.16. - С. 126-132.

9. Христенко Л.А. Применение метода редких сочетаний при интерпретации данных малоглубинной электроразведки // Горное эхо. - 2020. - № 2 (79). - C. 73-78. - DOI: 10.7242/echo.2020.2.15.

10. Hristenko L.A., Kichigin A.V., Parshakov E.I., Shiryaev K.N., Stepanov Y.I., Tainickiy A.A. Improvement of interpretation of the monitoring data electrical investigation by means of the theory of estimates // Engineering Geophysics 2017: $13^{\text {th }}$ Conference and Exhibition on Engineering Geophysics 2017. - Kislovodsk, 2017. - Code 129037. DOI: 10.3997/2214-4609.201700419.

11. Khristenko L.A., Stepanov Ju.I., Kichigin A.V., Parshakov E.I., Tainickiy A.A., Shiryaev K.N. Using of Probabilistic-Statistical Characteristics in the Interpretation of Electrical Survey Monitoring Observations // Practical and Theoretical Aspects of Geological Interpretation of Gravitational, Magnetic and Electric Fields: Proceedings of the 45th Uspensky International Geophysical Seminar, Kazan, Russia / ed. D. Nurgaliev, N. Khairullina; Kazan Federal University. - Springer, Cham, 2019. - P. 313-320. - (Book series: Springer Proceedings in Earth and Environmental Sciences). - DOI: 10.3997/2214-4609. 201700419. 